\title{
Non-Metastatic Epithelioid Sarcoma
}

National Cancer Institute

\section{Source}

National Cancer Institute. Non-Metastatic Epithelioid Sarcoma. NCI Thesaurus. Code C8800

Epithelioid sarcoma that is confined to the site in which it initially manifested. 